\title{
OPTIMAL AUTOMOBILE MUFFLER VIBRATION AND NOISE ANALYSIS
}

\author{
Sujit Kumar $\mathrm{Jha}^{1}$ and Ajay Sharma ${ }^{2}$ \\ ${ }^{1}$ Engineering Department, Ibra College of Technology, Ibra, Sultanate of Oman \\ E-mail:skj828@gmail.com \\ Tel: +968 25587924, Fax: +968 25549020 \\ ${ }^{2}$ Department of Mechanical and Automation Engineering, ASET, Amity University, \\ Noida, India
}

\begin{abstract}
The muffler is the main part of the Automobile Exhaust System, consisting of fibrous and porous materials to absorb noise and vibrations. The exhaust gas mass coming from the engine can produce resonance, which may be the source of fatigue failure in the exhaust pipe due to the presence of continuous resonance. The modes on the muffler should be located away from the engine's operating frequencies in order to minimise the resonance. The objective of this paper is to determine the frequencies that appear at the modes, which have the more adverse effect during the operation of the automobile. An impact test has been conducted by applying the force using a hard head hammer, and data generated have been used for plotting a graph of the transfer functions using MATLAB. Six points have been selected, namely 1, 2, 3, 4, 7, and 11 on the muffler for the impact test. The collected data from theses six points have been analysed for the addition of damping. Results suggests that increasing the mass increases the damping and lowers the modes of the transfer function. Further research will identify higher strength materials that can withstand the higher gas temperatures as well as the corrosion and erosion by the gas emitted from the engine.
\end{abstract}

Keywords: Automobile exhaust system; muffler; noise; vibration and modal analysis.

\section{INTRODUCTION}

An automobile exhaust system is used for silencing the levels of noise due to the high pressure hot and toxic gases leaving the engine. The exhaust pipe is subjected to stresses due to variations in noise level and hot gases coming out from the engine. The exhaust gas mass is forced through the pipe and introduces momentum forces by changes in the direction of motion, or in the expansion or contraction of the end pipe. The emitted gas coming out from the engine can produce resonance, which further causes fatigue failure in the exhaust pipe. Noise or sounds can be generated in the exhaust pipe due to the pulses of alternating high and low pressure of the gases leaving the engine. A pressure wave is generated when the exhaust valve repeatedly opens and allows the high pressure gas into the exhaust system. The generated pressure wave can produce sound, which can cause an increase in the engine rpm. The increase in engine rpm further causes pressure fluctuations and consequently the sound wave produced is of a high frequency. Apart from the exhaust system, noise can also be generated from other sources in an automobile, such as vibrations from the engine's body and transmission system. Flexible joints have been used to decrease the transmission of engine movements to the exhaust system. The muffler is located between the manifold and the catalytic converter, which can withstand high temperatures and should combine high flexibility with high 
strength and durability. Muffler design can be optimised by considering the pipe diameters, internal baffle locations, fracture characteristics, and by the presence of absorption material, etc. An optimised muffler design can be achieved by considering the reactive and absorptive properties of the muffler. Reactive or reflective mufflers apply destructive interference to reduce the noise level emitted by the engine. Reflections occur whenever there is a change in geometry or discontinuity in the area of the exhaust pipe. Muffler inlet and outlet tubes have perforations that allow sound pulses to scatter in numerous directions inside the chamber, resulting in destructive interference. An absorptive or dissipative muffler uses absorptive material to reduce the noise levels by converting sound energy into heat. A typical exhaust system is shown in Figure 1.

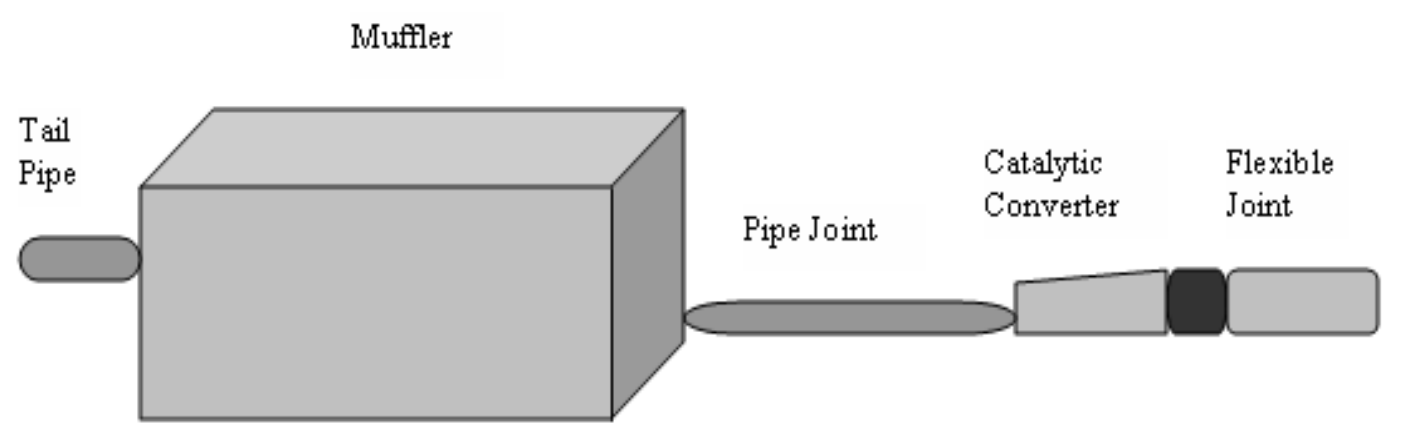

Figure 1. Typical exhaust system model.

The review of various articles on the impact testing of mufflers has been conducted and it is observed that vibration testing is very extensive. Ayadi et al. (2001) revealed the characterisation of a grating noise in an engine exhaust system by focusing on the problem with an experimental set up used for collecting data and investigation of the generated data. The objective behind this experiment is to determine the cause behind the rasping noise heard in exhaust systems during the abrupt acceleration of an automobile. The above analysis has been carried out to verify the occurrence of the rasping noise due to a balance between dissipative effects and nonlinear coupling between the exhaust system's resonance modes, which causes them to sustain each other. Wang et al. (2011) described the noise reduction of automobile gears using the fine-pitch profile optimisation method. Siano and Corcione (2005) implemented the Finite Element Method (FEM) to simulate and predict exhaust transmission noise. Lim (2000) used a spectral formulation on the theoretical interior acoustic sensitivity terms resulting from FEM, and measured the sound intensity. Citarella et al. (2007) presented an automobile vibro-acoustic analysis to assess, visualise and compare the vibroacoustic performance to predetermined design targets based on the experimental and numerical procedures used to identify the cause of this behaviour. Kim and Lee (1998) applied a noise reduction method based on the structural-acoustic response model, in which the automobile interior pressure was described in terms of modal parameters and structural-acoustic modal coupling coefficients. Shimura (1989) identified the various sources of noise in automobiles and stated how to reduce them. Lee and Lee (1993) determined the minimum energy transfer into a body by normal mode analysis using a theoretical approach. The objective of this research is to perform an impact test on the exhaust system to analyse the muffler system. According to the test results, the muffler 
design can be changed based on the resonant frequencies of the system. Impact force has been applied by a hammer, and an accelerometer has been used to measure the output response of the impact force. This research has used MATLAB to determine the resonance frequency and to plot a graph of the transfer functions by generating data from each point labelled on the muffler. Generally the plotted graph presents the transfer function and transfer function equivalent. This paper has considered a 2001 model Honda Civic car for the analysis of muffler design, to improve the comfort, efficiency and stylishness of the car.

\section{Dynamic Analysis of Muffler}

Mechanical structures subjected to dynamic loading cause undesirable vibration levels that can result in mild discomfort to structural breakdown. Resonance is an important phenomenon in structural dynamics, and can take place when a structure is excited at a frequency equal to its natural frequency. Each natural frequency is related to a specific deflection form, or a so-called mode shape. The response amplitude increases radically at resonance and is only restricted by the damping present in the structure, otherwise it lead to a failure of the structure. The dynamic analysis of the exhaust system can be done by exciting the structure in a proper way and concurrently measuring the excitation force and the resulting response in suitable degrees of freedom. The measured response is normally acceleration, since it is easy to measure. The next step is to determine the frequency content of the time signals measured and further frequency response functions calculated. Much research has been done on the dynamic analysis of exhaust systems. Verboven et al. (1998) presented experimental investigations on exhaust system dynamics, by comparing an ordinary experimental modal analysis with a running mode analysis. Deweer et al. (2001) performed an experimental modal analysis and highlighted the efficacy of theoretical models during the pre-test phase to conduct better experiments. Belingardi and Leonti (1987) studied the dynamic behaviour of the exhaust system by dealing with problems related to building finite elements. Piombo et al. (1986) investigated the coupling between the dynamic behaviour of the exhaust system and its fatigue resistance. An additional inclusive description of experimental modal analysis has been explained in detail (Ewins, 2000; Maia and Silva, 1997).

The modes of a muffler have been analysed in terms of a comfortable ride as well as to minimise the noise level. The modes occurring near an operating engine frequency should be avoided, as they can cause harmonic oscillations. Generally, the frequency at which a car engine operates is at $315 \mathrm{~Hz}$, corresponding to 3000 revolutions per minute (rpm). Similarly, the maximum frequency of a car engine is 838 $\mathrm{Hz}$ and the average idling frequency of a car engine is $73 \mathrm{~Hz}$. The paper has considered the above particulars and collected experimental data in the range of $60 \mathrm{~Hz}$ to $810 \mathrm{~Hz}$ using impact testing. Impact testing is a simple and fast method for obtaining highquality estimation of a system's modal properties and frequency response information. Data can be collected from labelled points in an exhaust system either by striking with an impact hammer or utilising an accelerometer on it.

\section{Research Approach}

In this paper, a hierarchical approach has been taken to conduct an experiment to collect data using an impact test on the muffler. For this, the first step is to determine any high transfer function values that take place during the operating frequencies of a car. After 
obtaining the transfer function values, the study of the design has been performed to shift the modes to higher frequencies ranges so that they are out of the car's operating range of frequencies. The range of frequencies determination should be between $73 \mathrm{~Hz}$ to $838 \mathrm{~Hz}$. After collecting data on the frequencies ranges, impact testing has been selected using a metal head hammer for findings the truth that mufflers are much damped to instigate with, so a stronger force is needed to achieve good vibration results. To study the acceleration data, Microsoft Excel has been used in combination with a piezoelectric accelerometer. A piezoelectric crystal accelerometer was selected based on its availability. For obtaining accurate data the accelerometer should be kept in a fixed position using a wax-based material.

This paper is organised as follows: in Section 2, details of the Design Principles of a Exhaust Muffler have been briefly discussed. Section 3 describes the Experimental Details. Section 4, provides a description of the Data Requirements for Muffler Design in the proposed method, and Data Analysis and Observations have been presented in Section 5. Followed by conclusions in Section 6.

\section{DESIGN PRINCIPLES OF AN EXHAUST MUFFLER}

A car engine generates high intensity pressure waves transmitted through the exhaust pipe and radiated to the environment. The frequency of the generated pulse recurs at the firing frequency of the engine, given as $f=$ (engine $\mathrm{rpm} \times \mathrm{x}$ number of cylinders) $/ 120$ for a four-stroke engine. The exhaust noise frequency is subjugated by a pulse at the firing frequency as well having a broadband module in its spectrum which widens to higher frequencies. Exhaust pipe pressure pulse measurements on a car engine show that the majority of the pulse energy lies in the frequency range of 0-600 Hz. Exhaust mufflers are designed to reduce the sound levels at these frequencies. The sound waves propagating through a pipe can be soothed using either a dissipative or reactive muffler. Sound absorbing materials have been used in dissipative mufflers for taking energy from the acoustic motion of the wave during its propagation through the muffler. Generally, reactive silencers used in automobiles replicate the sound waves back towards the source and prevent sound from being sent out of the pipe. The design of reactive silencers is either based on the principle of a Helmholtz resonator or an expansion chamber, which further requires the use of acoustic transmission line theory.

A cavity is added to the exhaust pipe during the design of a Helmholtz resonator. The cavity will resonate at a particular frequency, and the waves in the exhaust pipe are returned back towards the source. According to some designers, the muffler has a number of resonators of different sizes to target a range of frequencies. Due to sudden changes in the cross-sectional area in the pipe, the expansion chamber mufflers reflect the waves, which have a broadband frequency characteristic but do not have the high attenuation of the Helmholtz resonator. The tailpipe length has significant role in muffler design, which acts as a resonant cavity that links with the muffler cavity. The effect of exhaust gas flow speed has a detrimental effect on muffler performance. According to Beranek and Istvan (1992), the muffler attenuation can be decreased from $35 \mathrm{~dB}$ to $6-10 \mathrm{~dB}$ as the flow speed increases from 0 to $230 \mathrm{ft} / \mathrm{sec}$.

\section{Typical Muffler Design}

The paper has considered the design of two distinctive reactive mufflers, which are shown in Figures 2 and 3. The first design is shown in Figure 2, to illustrate a design 
which offers a lower back pressure and low cost of manufacture. According to an acoustic stand point, multiple cavities of the muffler shown in Figure 2 are connected to the exhaust pipe by holes drilled in the central tube. Whenever hot gases pass through the exhaust pipe, a vertical flow can also be formed through each hole connecting the pipe to reduce the insertion loss of the muffler.

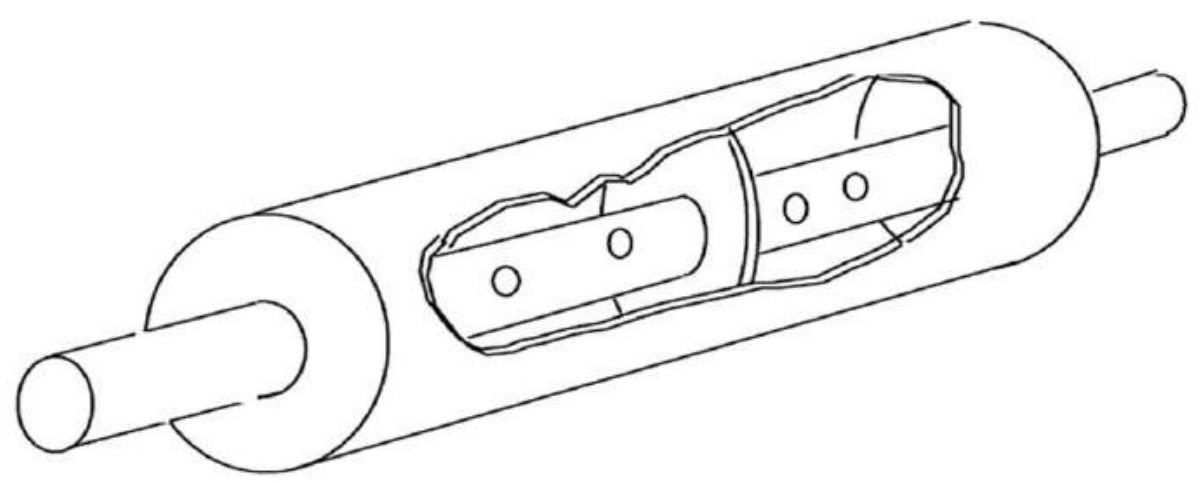

Figure 2. A reactive muffler connecting two cavities.

The second kind of reactive muffler is shown in Figure 3, which gives extra attenuation and is generally recommended by muffler manufacturers. Due to the no direction connection between the inlet and the outlet, the generated back pressure can affect engine performance.

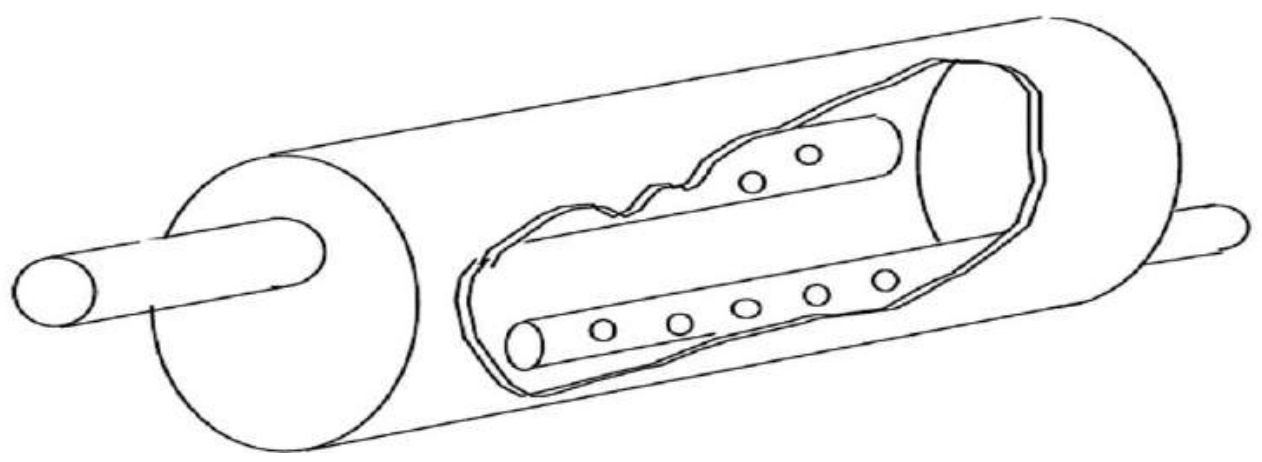

Figure 3. A reactive muffler with no direction connection between the inlet and outlet.

The muffler shown in Figure 2 generates a minimal back pressure, while the other type shown in Figure 3 creates $1.4 \pm 0.3$ psi of back pressure.

\section{Functional Requirements of an Engine Exhaust Muffler}

Many functional requirements have been considered during the design of a muffler, like adequate insertion loss, back pressure, size, durability, desired sound, cost, shape and style. The main objective of a muffler is to attenuate sound, i.e. minimise the intensity of the sound pressure of the noise source to a desired level. The attenuating capability of a muffler is identified in terms of an insertion or transmission loss. Insertion loss is the difference between the acoustic powers emitted with and without a muffler attachment. Similarly, the difference between the intensity of sound incidents at the entrance to the muffler to that transmitted by the muffler is the transmission loss. Due to the restriction 
in the flow of exhaust gases, the additional static pressure exerted by the muffler to the engine is defined as the back pressure. To avoid more power losses in the exhaust system, the back pressure should be as low as possible. The size of a muffler plays a great influence on the utilisation of the available space, it should meet the space constraints otherwise it is useless. Mufflers deal with hot toxic gases so its durability is also important, and applications of absorptive silencers are significantly found in performance vehicles. The materials used for mufflers must be corrosion resistant, like stainless steel or aluminium alloys, and must also sustain higher temperatures, like mild steel and aluminium up to $500^{\circ} \mathrm{C}$ and improved material compositions can resist temperatures up to $750^{\circ} \mathrm{C}$.

\section{EXPERIMENTAL DETAILS}

The first step is to generate the coordinates for the geometry of the system. All the marked points are important during carrying out the impact test in order to obtain adequate values for displaying all the significant modes and resonant frequencies of the system. At the same time further data points should be avoided, otherwise the acquisition of data becomes meaningless or redundant in its analysis. Labelling on the muffler geometry should be as accurate as possible, so that data can be taken from the exact location of the marked points. In this research there are 12 data points that represent the experimental geometry, as determined by Fredrick and Brady (2003). Figure 4 illustrates the points labelled on the muffler for the collection of data using the impact test.

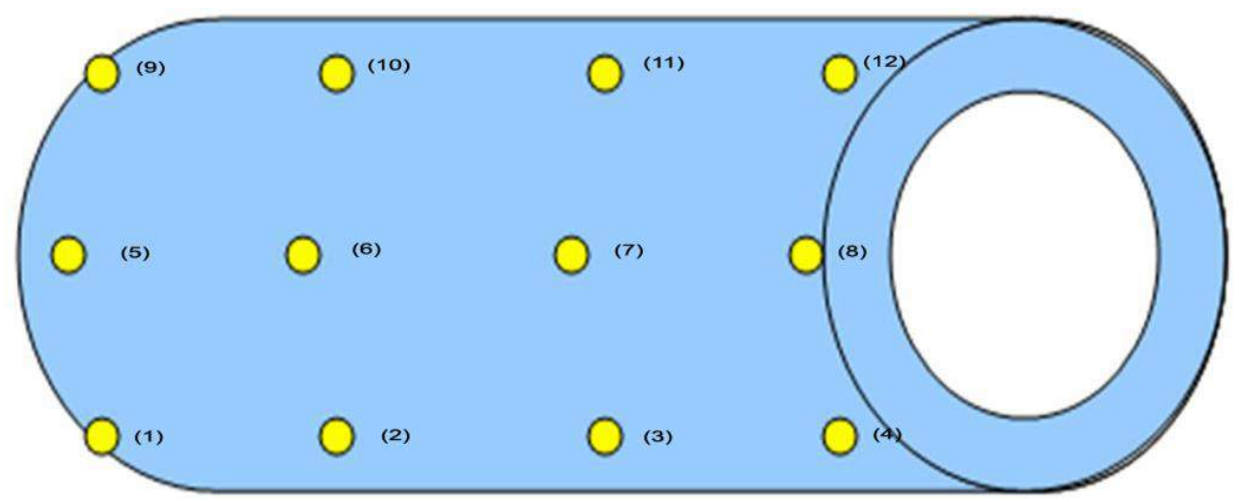

Figure 4. Labelled points on the muffler for testing.

For conducting the experiment it is important to select the testing parameters like sampling rate, which should be high to increase the resolution and get better precision of the data as smaller step size in-between the data points taken. During the experimental process a sampling rate of $2000 \mathrm{~Hz}$ has been used. During the performance of the impact test, the system must be isolated correctly so that accelerometer can only experience acceleration due to the vibrations from the impact test and not from other sources. For this purpose, foam has been used to dampen vibrations from the neighbouring environment. Noise interference is inherent in heavily dampened systems, which cannot be completely eliminated, but by implementing an analysis tool such as the equivalent transfer function graph it is possible to eliminate some of the effects from the analysis. 
The components of vehicles and structures subjected to cyclic loads lead to mechanical vibrations. Lateral vibrations can be transmitted to body panels through mounts and torsional vibrations to the body by the vehicle's structure. Linear vibration can be measured using accelerometers, which are contact type transducers made from quartz crystals to give a high frequency response. Accelerometers are widely used as an acceleration output, which is directly proportional to the applied force's frequency on its output. For modal testing, light-weight accelerometers must be used to avoid the mass loading effect. The paper has considered a single accelerometer in impact testing, if placing the accelerometer on the muffler at the point labelled 1 it is very difficult to ensure that the accelerometer is facing towards the z-axis as the point is at an angle. To avoid this, the accelerometer has been placed at the point labelled 6 , since it is parallel to the ground so the accelerometer can face directly vertical. As data collection commences, a problem may occur due to a loose connection between the accelerometer and the computer. When performing the impact test, it is important to handle the impact hammer in proper way for collecting accurate data. During the test, care should take to avoid the repeated striking of the hammer, which can cause the vibration of the system. The single impact of the hammer is always preferable to avoid the data being a summation of multiple impacts on the system. One further problem can occur if the hammer is not able to hit the system in the direction of the Z-axis, i.e. vertically, which will alter the vibration properties in each direction and accurate results cannot be obtained. The accelerometer is able to measure the vibrations along one axis at a time. For maximum vibration, the hammer should impact properly in one direction alone, and then accurate resonant frequencies of the impacts along this axis can be obtained (Fredrick and Brady, 2003).

\section{DATA REQUIREMENTS FOR MUFFLER DESIGN}

\section{Performance characteristics}

Insertion loss (IL) is defined as a reduction in noise level that occurs by inserting a silencing element into the system. Insertion loss varires from engine to engine, normally it changes according to a change in the engine load or from different piping configurations of the muffler. By changing the engine load, the engine exhaust noise also changes and the noise level at full load is about $10 \mathrm{~dB}$ higher than in the no-load condition. The unsilenced engine exhaust system creates a noise level around $110 \mathrm{~dB}$ when measured at $1 \mathrm{~m}$ from the pipe outlet. The insertion loss in an exhaust system depends on the design, size and frequency generation of the muffler, and the pressure drop at the two ends of the muffler depends on the velocity of the emitted gas and design features of the muffler. Figure 5 shows the sound levels of the engine exhaust system at different loads for a 16-cylinder engine (1800 RPM diesel). 


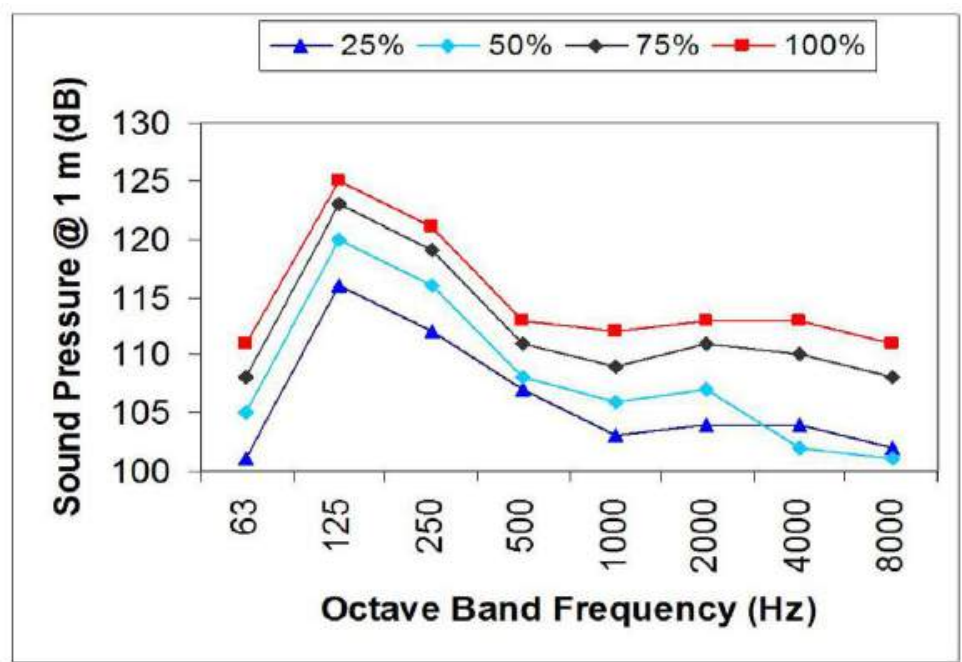

Figure 5. Unsilenced exhaust noise: "noise level vs. load".

\section{Unsilenced exhaust noise}

According to the engine firing order, the exhaust noise level can contain strong tones. Each cylinder in a 4-cycle engine fires once at every other revolution of the crank shaft, whereas in a 2-cycle engine the cylinder fires once every revolution of the crank shaft. Unsilenced engine exhaust noise is broadband, with the highest levels at low frequencies. The lowest tone is always the cylinder firing rate (CFR), which is the firing rate for any individual cylinder. The strongest tone in the exhaust system is the engine firing rate (EFR). Figure 6 shows the unsilenced exhaust noise and illustrates that the noise level never lines up with the power rating of the generator. It is always advisable to obtain exhaust noise data from the engine's manufacturer. The Figure 6 also illustrates data comparing a 6-cylinder $150 \mathrm{KW}$ engine with a 16 -cylinder $2000 \mathrm{KW}$ engine.

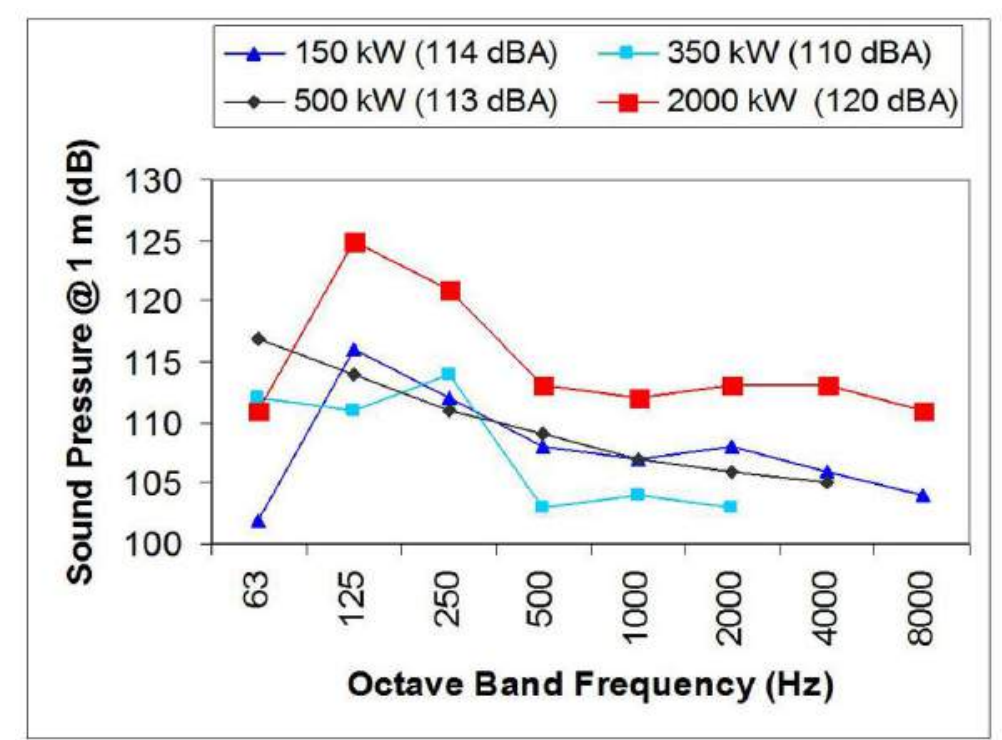

Figure 6. Unsilenced exhaust noise. 


\section{Engine Exhaust Tone}

Figure 7 shows a graph of the narrow band spectrum of the exhaust noise level of a 6cylinder diesel engine running at $1800 \mathrm{RPM}$ in a $500 \mathrm{KW}$ generator. When the engine is running at full load, a microphone is placed at 1 metre from the exhaust outlet and data is collected. The strong tone can be achieved at $90 \mathrm{~Hz}$, which is the engine firing rate (EFR) and can be defined as: $\mathrm{EFR}=\mathrm{N} \times$ cylinder firing rate $(\mathrm{CFR})$. The cylinder firing rate can be given as: $\mathrm{CFR}=\mathrm{RPM} / 60$ for a 2-cycle engine and RPM/120 for a 4-cycle engine.

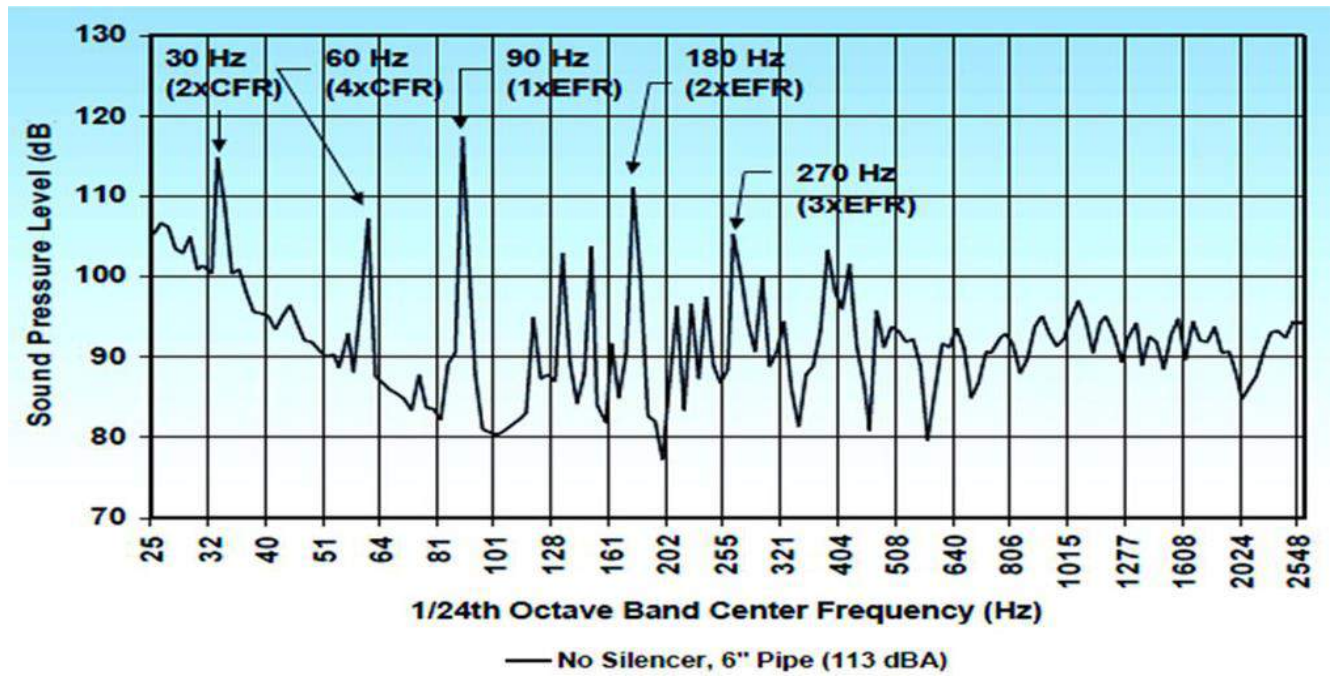

Figure 7. Band spectrum of the exhaust noise.

Reactive mufflers are an important element used to silence generator exhausts. The varieties of reactive mufflers available are based on the cost and performance of the exhaust system. The noise can be reduced by forcing the exhaust air to pass through a series of tubes and chambers. Generally absorptive silencers employ fibreglass or other acoustic fill material to absorb all generated noise without any reactive elements. Due to the low capability of absorptive noise reduction at low frequencies it has limited use.

\section{Tail Pipe Design}

Normally the acoustical design of an engine exhaust system often ignores the tail pipe. The section of pipe downstream of the final silencer will have acoustic resonances that can amplify the engine tones if they match. The resonances can be avoided by maintaining the length of the tail pipe to less than $1 / 2$ wavelengths of the tone frequency.

1. Engine tone can be increased if the exhaust tail pipe has a resonance

2. Amplification of tones can be avoided by using a short tail pipe or $L$ to $1 / 4$ wavelength $(\lambda / 4)$.

The following equation gives the various resonance frequencies of an exhaust tail pipe. $f_{n}=\frac{n \cdot c}{2 L}$, where $f_{n}$ is the resonance frequency of the pipe, $c$ is the speed of sound, $L$ is the length of the pipe in feet and $n=1,2,3 \ldots$, Generally, resonance occurs if $L=n \lambda / 2$ 


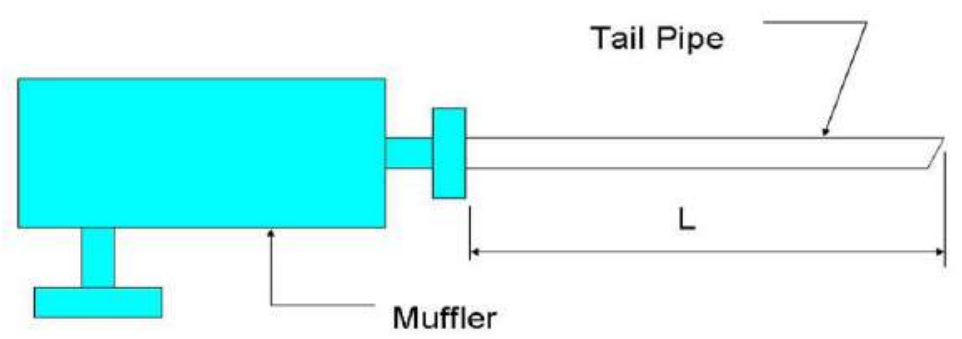

Figure 8. Length of tail pipe.

Many steps are required in the design of a tail pipe for a 4-cycle engine using the above principles. For the optimal design of a muffler, the following frequencies should be avoided $15 \mathrm{~Hz}, 30 \mathrm{~Hz}, 45 \mathrm{~Hz}, 60 \mathrm{~Hz}, 75 \mathrm{~Hz}, 90 \mathrm{~Hz}, 105 \mathrm{~Hz}$, etc. in order to avoid the resonance. From all the frequencies, the most important frequency is $90 \mathrm{~Hz}$ EFR. The wavelength at $90 \mathrm{~Hz}$ is 20 feet, so the length of the tail pipe must be exactly 5 feet to avoid resonance.

\section{Helmhotz Equation for Acoustic Analysis}

The basic equation used for acoustic wave propagation through an elastic medium is given as:

$$
\nabla^{2} u=\frac{1}{c^{2}} \frac{\partial^{2} u}{\partial t^{2}}+b
$$

Where $u(x, t)$ is the velocity potential, $\mathrm{c}$ is the speed of sound, $b(x, t)$ is the sound source, and $x$ and $t$ are the position and time variables. Assuming that the problem is time harmonic, Eq. (1) can be transferred to the frequency domain in order to obtain the Helmholtz equation: $\nabla^{2} u+k^{2} u=b$

Where $k=\omega / \mathrm{c}$ is the wave number and $\omega=2 \pi \mathrm{f}$ the angular frequency. The boundary conditions of the problem have been discussed in detail by Hamdi (1981).

\section{OBSERVATIONS BASED ON DATA ANALYSIS}

The data collected from impact test first interpret to set up transfer functions for each data point on the muffler then taken distinguish of the resonant frequencies occurred at each spot. The transfer function plot is a graph of the force exerted on the system by the impact hammer over the acceleration of the muffler system with respect to the frequency, and has been plotted using MATLAB. The transfer function graph and the equivalent transfer function graph are shown in Figures 9 and 10 for the first point on the muffler, and similarly all other points based on the data collected for these points have been plotted and are shown in Appendix A. 


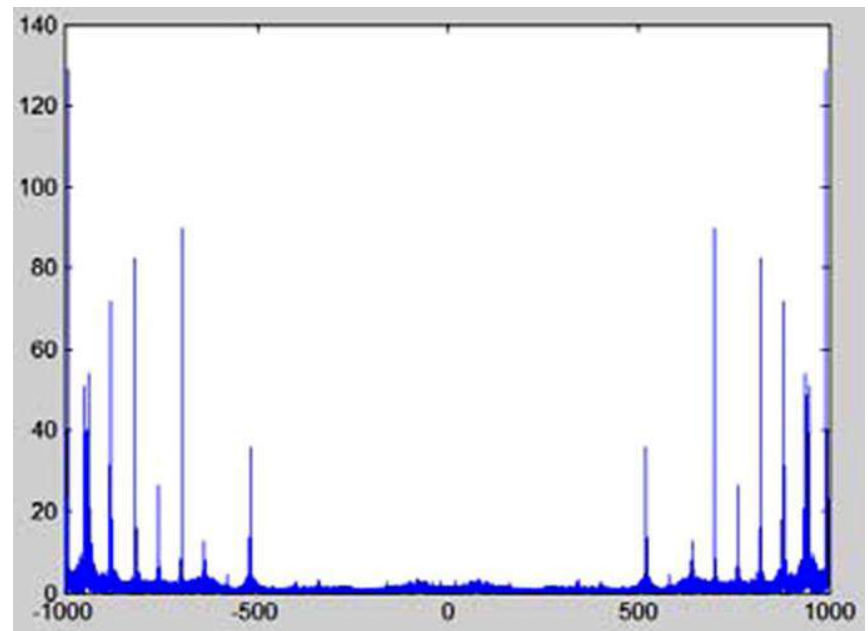

Figure 9. Transfer function graph.

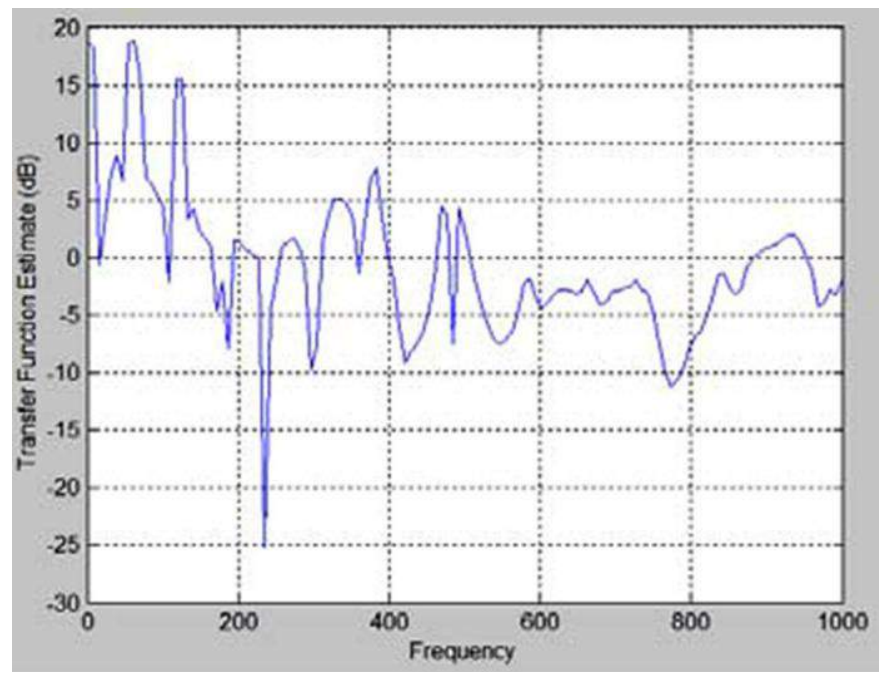

Figure 10. Equivalent transfer function graph.

Based on Fredrick and Brady (2003), the experimental steps and plotting of the graph have also been taken as the basis for this research. During the plotting of the graph the accelerometer data has been divided by the calibration constant $(110.3 \mathrm{mV} / \mathrm{g})$ of the accelerometer used in the experimental process. The graph shows the peaks at all multiple values of frequency of $60 \mathrm{~Hz}$. The graph shows the peaks due to an electrical frequency in the neighbouring environment, building these individual graphs very hard to interpret. The transfer function can be plotted by converting the readings from the time domain to the frequency domain, which can be done by dividing the Fourier transfer of the input by the Fourier transfer of the output. The MATLAB function has been used to achieve the desired result and build plots of the accelerometer/hammer with respect to frequency, by giving a desired graph of the output/input with respect to frequency. The equivalent transfer function graph has been used as a second source for interpreting the data. Table 1 presents the peaks in the transfer function in order to determine those frequencies most frequently exciting the peaks in the transfer function. 
Table 1. Collection of the data sets to determine the peaks in the transfer function.

\begin{tabular}{|c|c|c|c|c|c|c|c|c|c|c|c|c|c|c|}
\hline \multirow[t]{2}{*}{ Mode } & $\begin{array}{l}\text { Data } \\
\text { Set } 1\end{array}$ & $\begin{array}{l}\text { Data } \\
\text { Set } 2\end{array}$ & $\begin{array}{l}\mathrm{D} \\
\mathrm{Se}\end{array}$ & & $\begin{array}{l}\text { Data } \\
\text { Set } 4\end{array}$ & $\begin{array}{l}\text { Data } \\
\text { Set } 5\end{array}$ & $\begin{array}{l}\text { Data } \\
\text { Set } 7\end{array}$ & & $\begin{array}{l}\text { ata } \\
\text { et } 8\end{array}$ & $\begin{array}{l}\text { Data } \\
\text { Set } 9\end{array}$ & $\begin{array}{c}\text { Data } \\
\text { Set } 10\end{array}$ & & $\begin{array}{l}\text { ata } \\
\text { t } 11\end{array}$ & $\begin{array}{c}\text { Data } \\
\text { Set } 12\end{array}$ \\
\hline & M1 M2 & M1 M2 & M1 & M2 & M1 M2 & M1 M2 & M1 M2 & M1 & M2 & M1 M2 & M1 M2 & M1 & M2 & M1 M2 \\
\hline 1 & 52070 & 240240 & 5 & 8 & 8 & 250245 & $\begin{array}{ll}15 & 10\end{array}$ & 10 & 50 & 25560 & 420420 & 520 & 30 & 325125 \\
\hline 2 & 700120 & 290440 & 80 & 120 & 11070 & 395340 & $40 \quad 60$ & 440 & 70 & 275115 & 585585 & 580 & 120 & 360410 \\
\hline 3 & 820275 & 300515 & 97 & 180 & 120120 & 520400 & $90 \quad 80$ & 640 & 100 & 400185 & 995885 & 640 & 165 & 420580 \\
\hline 4 & 880340 & 310590 & 102 & 240 & 130180 & 750450 & 12090 & 920 & 180 & 700235 & 910 & 700 & 240 & 850635 \\
\hline 5 & 940375 & 350650 & 120 & 270 & 160230 & 930510 & 140120 & 930 & 220 & 760295 & 975 & 760 & 33 & 860670 \\
\hline 6 & 990470 & 550680 & 270 & 325 & 200290 & 1000555 & 150180 & 940 & 290 & 880405 & & 820 & 560 & 990800 \\
\hline 7 & 495 & 730760 & 535 & 460 & 220310 & 630 & 170230 & 950 & 310 & 940445 & & 880 & 595 & 995865 \\
\hline 8 & 575 & 790880 & 650 & 610 & 300320 & 820 & 220275 & 960 & 370 & 600 & & 940 & 725 & 890 \\
\hline 9 & 675 & 990980 & 710 & 680 & 310350 & 870 & 440295 & 970 & 410 & 710 & & 1000 & 930 & 990 \\
\hline 10 & 730 & & 1000 & 730 & 320375 & 930 & 490320 & 990 & 560 & 745 & & & 1000 & \\
\hline 11 & 840 & & & 760 & 360420 & & 505360 & & 750 & 880 & & & & \\
\hline 12 & 940 & & & 800 & 390445 & & 560420 & & 830 & 930 & & & & \\
\hline 13 & 990 & & & 840 & 420480 & & 575480 & & 900 & & & & & \\
\hline 14 & & & & 890 & 455500 & & 590510 & & 960 & & & & & \\
\hline 15 & & & & 920 & 460540 & & 599540 & & 1000 & & & & & \\
\hline 16 & & & & 960 & 600560 & & 600550 & & & & & & & \\
\hline 17 & & & & & 620600 & & 610560 & & & & & & & \\
\hline 18 & & & & & 680620 & & 620600 & & & & & & & \\
\hline 19 & & & & & 780680 & & 670620 & & & & & & & \\
\hline 20 & & & & & 880720 & & 690655 & & & & & & & \\
\hline & & & & & 970780 & & 700690 & & & & & & & \\
\hline & & & & & 810 & & 715715 & & & & & & & \\
\hline & & & & & 870 & & 720730 & & & & & & & \\
\hline & & & & & 900 & & 730780 & & & & & & & \\
\hline & & & & & 920 & & 750820 & & & & & & & \\
\hline & & & & & 960 & & 770850 & & & & & & & \\
\hline & & & & & 980 & & 790860 & & & & & & & \\
\hline & & & & & & & 800920 & & & & & & & \\
\hline & & & & & & & 825960 & & & & & & & \\
\hline & & & & & & & 840980 & & & & & & & \\
\hline & & & & & & & 870 & & & & & & & \\
\hline
\end{tabular}

The problems encountered during impact testing are generally the aliasing error and leakage error. According to Shannon's sampling theorem or Nyquist's criterion, the sampling frequency for a system requirement should be twice the maximum frequency to be measured, otherwise an aliasing error will occur. Leakage errors occur whenever the collection of data is stopped before the energy of the system has diminished. This causes inaccuracies in the transfer function. During the performance of the vibrations test, the objective is to minimise the amount of leakage error for all systems. This is an added reason for isolating the muffler system with enveloping foam. Before starting the experiment, the range of frequency from 0 to $1000 \mathrm{~Hz}$ has been selected for the analysis of frequencies that are usually encountered by a vehicle.

Table 2 shows the most frequently occurring peaks and the number of data points at which that peak occurred. First select the peaks that occur frequently by selecting the most significant resonance frequencies. Then select the peaks over a wide range of frequencies in order to eliminate a good range of problem spots. Finally, it is desirable to eliminate those peaks that are frequently the highest in the graphs, which may cause problems in the system. The frequency range for this experiment was from 0 to $1000 \mathrm{~Hz}$, but the paper is mostly concerned with points below about $800 \mathrm{~Hz}$ since these are the ones most likely to be achieved by the system. By considering these 
criteria five resonance frequency peaks were selected: as $120 \mathrm{~Hz}, 420 \mathrm{~Hz}, 560 \mathrm{~Hz}, 730$ $\mathrm{Hz}$, and $880 \mathrm{~Hz}$, which can be removed from the system. Although the peak at $880 \mathrm{~Hz}$ is somewhat outside the research range of interest, there are a large number of peaks at this point, was and it is fairly close to the range of interest, and thus it remained a one of the peaks targeted (Fredrick and Brady, 2003).

Table 2. Most frequently occurring peaks and data points where peaks occurred.

\begin{tabular}{cccc}
\hline Frequency & Points on muffler & $\begin{array}{c}\text { Number } \\
\text { of times }\end{array}$ & $\begin{array}{c}\text { Number of occurrences at } \\
\text { resonance frequencies }\end{array}$ \\
\hline 70 & $1,4,8$ & 3 & 2 \\
$\mathbf{1 2 0}$ & $\mathbf{2 , 3}, \mathbf{4}^{*}, \mathbf{7}^{*}, \mathbf{1 1}$ & $\mathbf{5}$ & $\mathbf{3}$ \\
240 & $2^{*}, 3,11$ & 3 & 2 \\
$\mathbf{4 2 0}$ & $\mathbf{1 0}^{*}, \mathbf{1 2 , 4} \mathbf{4}^{*}, \mathbf{7}$ & $\mathbf{4}$ & $\mathbf{4}$ \\
$\mathbf{5 6 0}$ & $\mathbf{1 1 , 8 , 7 * , 4}$ & $\mathbf{4}$ & 0 \\
600 & $9,4^{*}, 7^{*}$ & 3 & 0 \\
$\mathbf{7 3 0}$ & $\mathbf{1 , 2 , 3 , 7 *}$ & $\mathbf{4}$ & $\mathbf{4}$ \\
760 & $9,11,2,3$ & 4 & 1 \\
820 & $1,11,5,7$ & 4 & 1 \\
$\mathbf{8 8 0}$ & $\mathbf{1 , 9 *}, \mathbf{1 1 , 2 , 4}$ & $\mathbf{5}$ & 1 \\
920 & $8,3,4,7$ & 4 & $\mathbf{3}$ \\
930 & $5^{*}, 8,11,9$ & 4 & 1 \\
940 & $1^{*}, 8,9,11,7$ & 5 & \\
960 & $8^{*}, 4,7,3$ & 4 & \\
990 & $1^{*}, 12^{*}, 2,8,7$ & 5 & \\
1000 & $5,11^{*}, 3,8$ & 4 & \\
\hline
\end{tabular}

\section{CONCLUSIONS}

An effort has made to review the various techniques used for the measurements of noise and vibrations of an automobile. This research conducted experiments to analyse a muffler system with impact testing. The impact force has been applied by a hammer and an accelerometer has been used to determine the output response. According to the test results, the muffler design can be changed based on the resonant frequencies of the system. MATLAB has used to determine the resonance frequency and to plot a graph of the transfer functions for each data point labelled on the muffler. From the collected data sets in Table 2, five peaks have occurred at 120,240,560,730, and $880 \mathrm{~Hz}$, which were identified as prospective resonance frequencies to be eliminated from the muffler system. Furthermore, the resonance frequencies can be minimised by adding damping to the system. The location of the points on muffler surface for estimating the damping have been determined as points 1, 2, 3, 4, 7, and 11, as shown in Figure 4.

\section{REFERENCES}

Ayadi, M., Frikha, S. and Hennion, P.Y. 2001, Characterization of rasping noise in automotive engine exhaust ducts, Journal of Sound and Vibration, 244(1), 28.

Belingardi G. and Leonti, S. 1987, Modal analysis in the design of an automotive exhaust pipe, International Journal of Vehicle Design, 8(4/5/6), 475-484. 
Beranek, L. L. and Istvan, V.L. 1992, Noise and Vibration Control Engineering: Principles and Applications, John Wiley \& Sons, 818 p.

Citarella, R., Federico, L. and Cicatiello, A. 2007, Modal acoustic transfer vector approach in a FEM-BEM vibro-acoustic analysis, Engineering Analysis with Boundary Elements, 31, 248-258.

Deweer, J., Van Langenhove, T. and Grinker, S. 2001, Identification of the best modal parameters and strategies for FE modal updating, Proceedings of the SAE Noise \& Vibration Conference \& Exposition, Grand Traverse, USA.

Ewins, D.J. 2000, Model testing: theory, practice and application, Second edition, Research Studies Press, Baldock, UK.

Fredrick, A. and Brady, S. 2003, Design project on vibration analysis on automobile muffler, EGR 315, Mechanical Vibrations, Miami University.

Hamdi, M.A. 1981, A vibrational formulation by integral equations for the solutions of the Helmholtz equation with mixed boundary conditions (in French), Comptes rendus Academie ds Sciences, 292.

Kim, S.H. and Lee, J.M. 1998, A practical method for noise reduction in a vehicle passenger compartment, Journal of Vibration and Acoustics, 120, 199-205.

Lee, S. S. and Lee, C. M. 1993, A study on determining hanger positions of exhaust system and the effect of bellows, Journal of Korea Society of Automotive Engineers.

Lim, T.C. 2000, Automotive panel noise contribution modeling based on finite element and measured structural-acoustic spectra, Applied Acoustics, 60, 505-519.

Maia, N.M.M. and Silva, J.M.M. 1997, Theoretical and experimental modal analysis, Research Studies Press, Baldock, UK.

Piombo, B., Belingardi, G., Dardano, R. \& Pavese, M. 1986, Automotive exhaust pipe: the modal analysis approach for design and testing, Proceedings of the International Modal Analysis Conference (IMAC), Los Angeles, USA.

Shimura, A., 1989, Radiation noise due to longitudinal vibration of the exhaust pipe, SAE, 852266.

Siano, D. and Corcione, E.F. 2005, FE fluid-structure interaction/experimental transmission loss factor comparison of an exhaust system, Proceedings of the 7th International Conference on Engines for Automobile (ICE2005).

Verboven, P., Valgaeren, R., Van Overmeire, M. and P. Guillaume, 1998, Some comments on model analysis applied to an automotive exhaust system, Proceedings of the International Modal Analysis Conference (IMAC), Santa Barbara, USA.

Wang, T., Zhao, F.Q., Zhang, R. and Qi, L. 2011, Optimization design method of noise control on fine-pitch gear, Open Mechanical Engineering Journal, 5, 103-107. 


\section{Appendix A}

Transfer Function and Equivalent Transfer Function Graph

Point 1
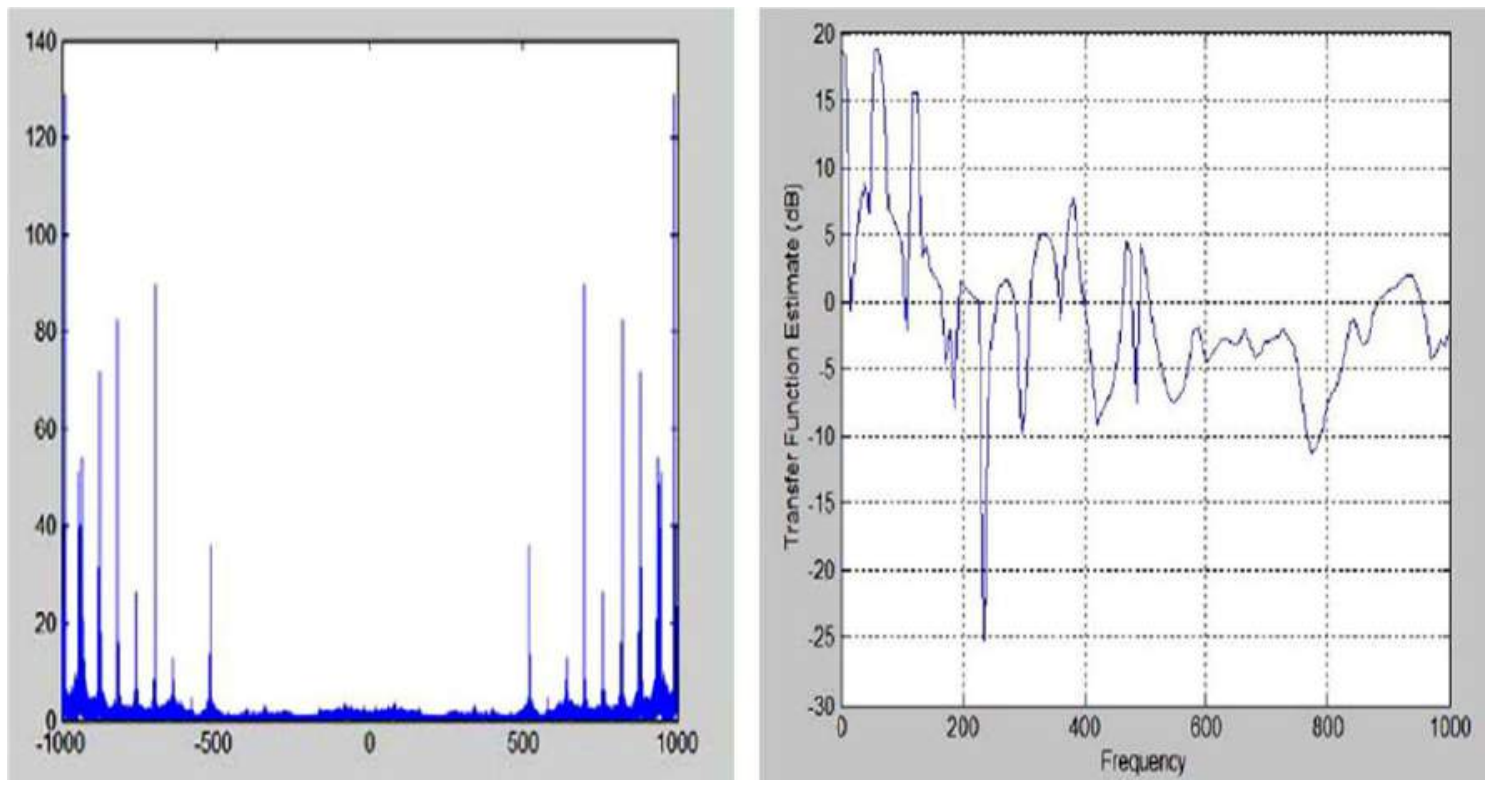

Point 2
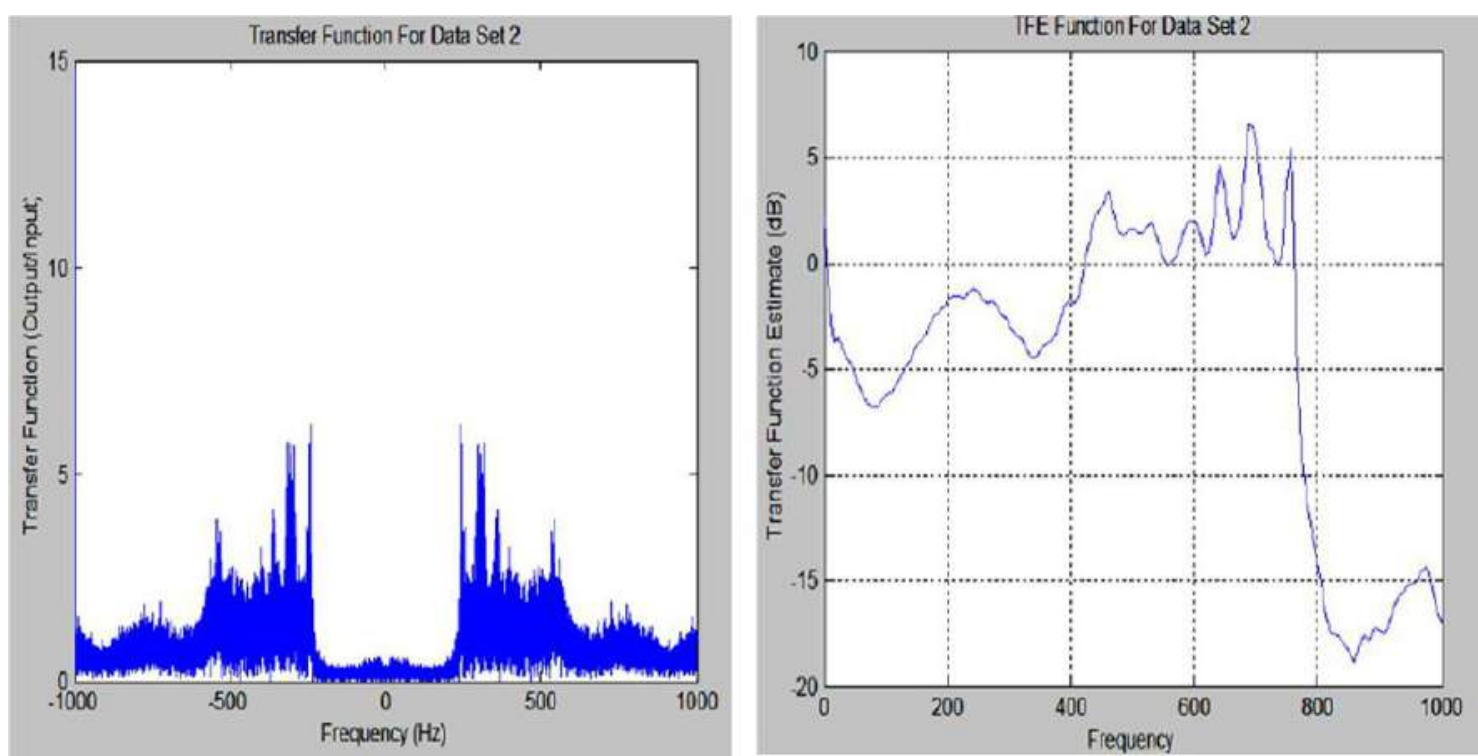
Point 3
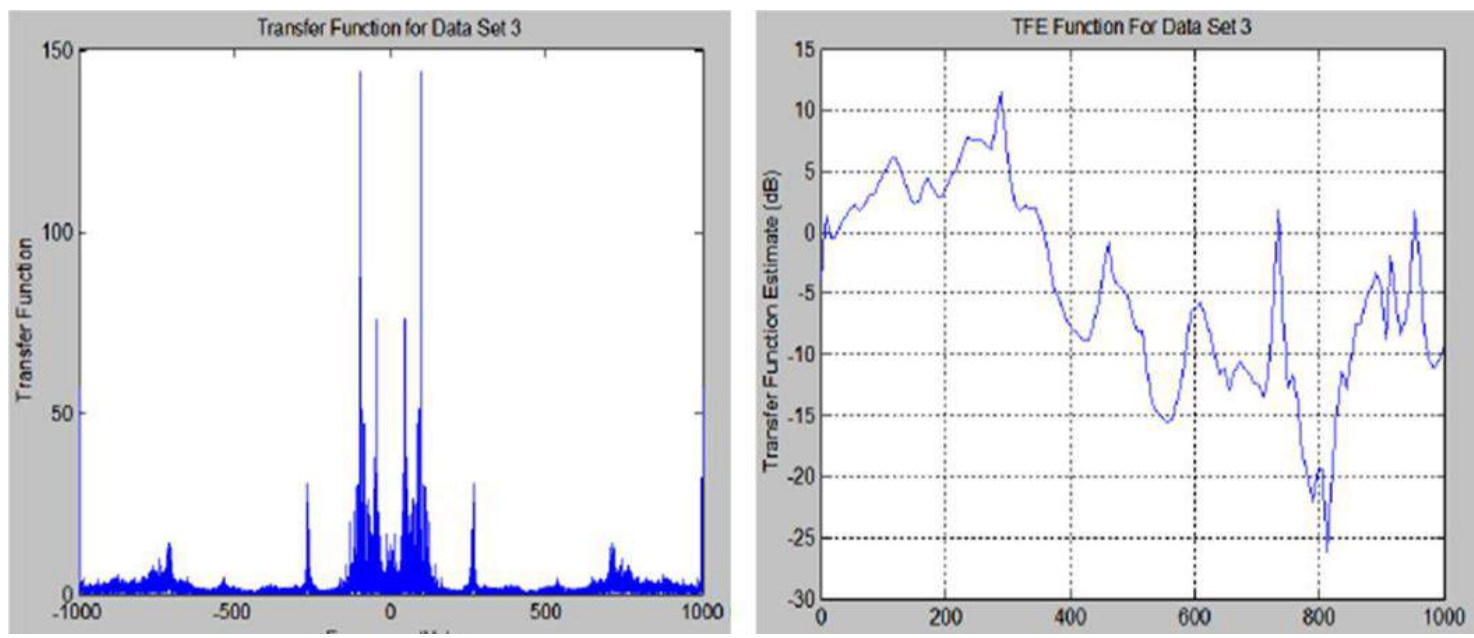

Point 4
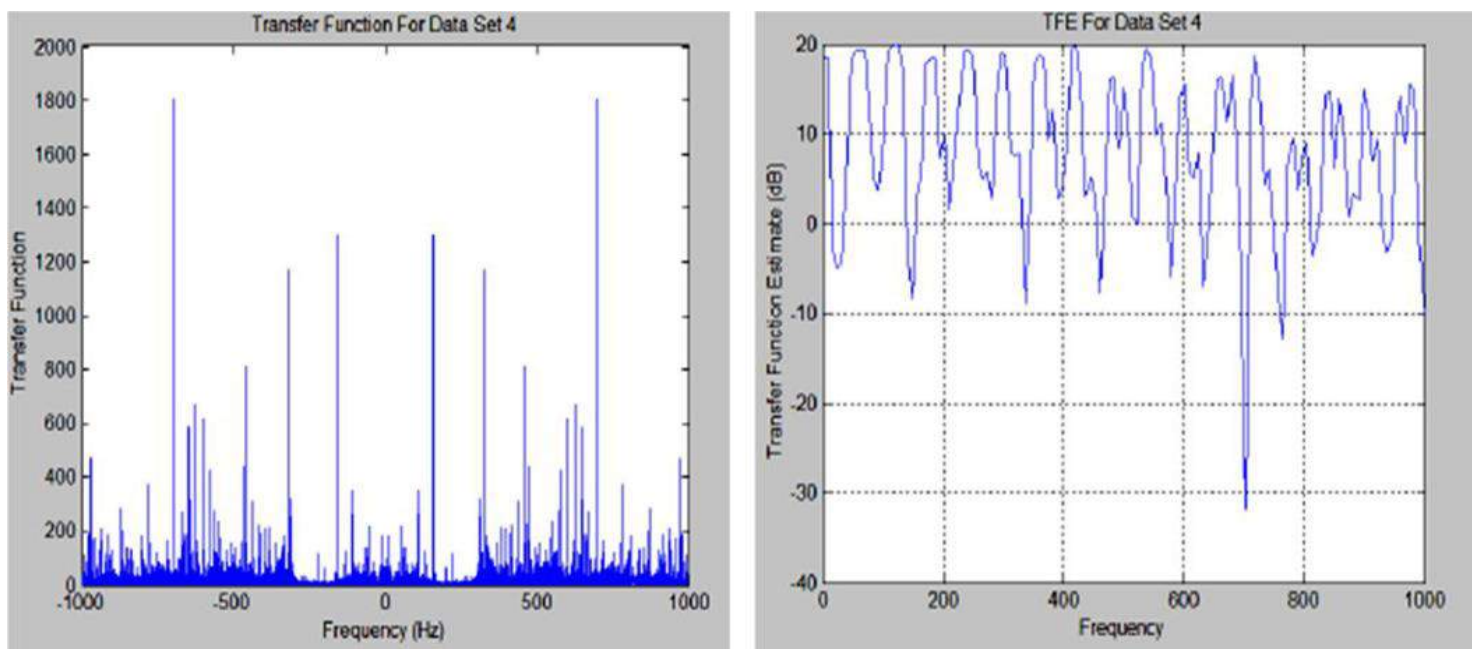

\section{Point 5}
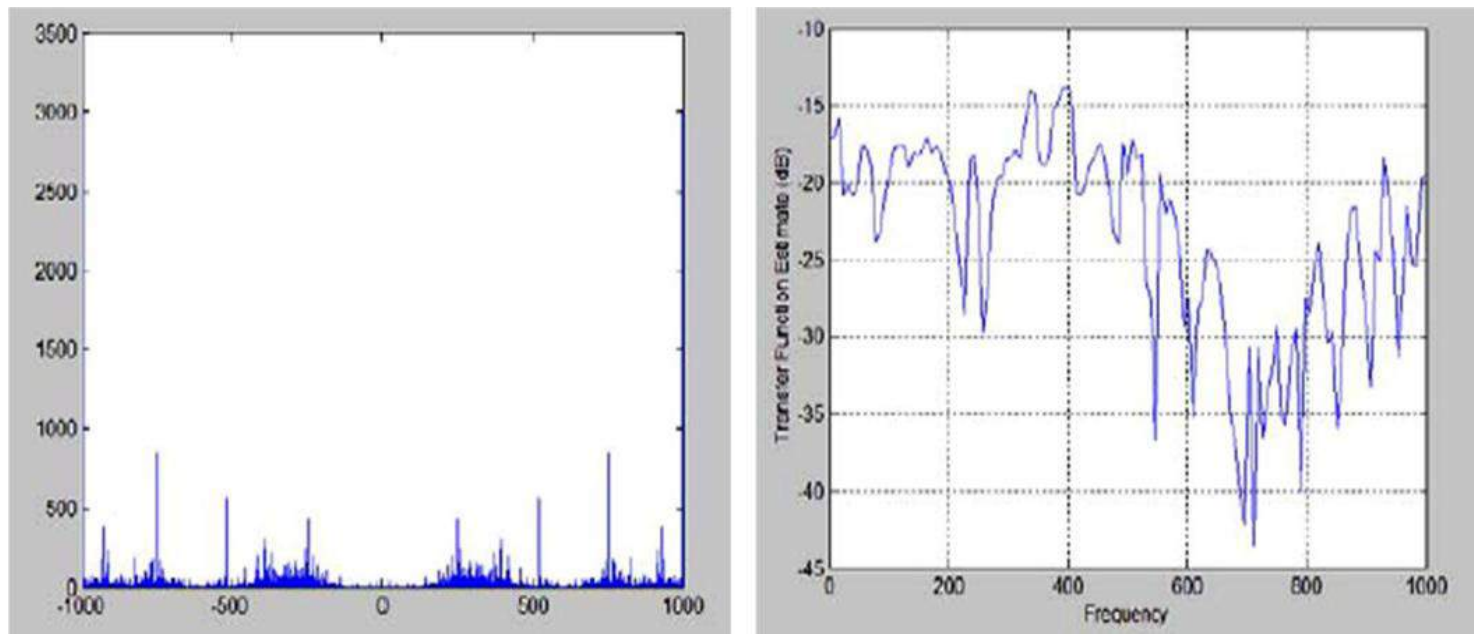
Point 6

Where the accelerometer was placed

Point 7
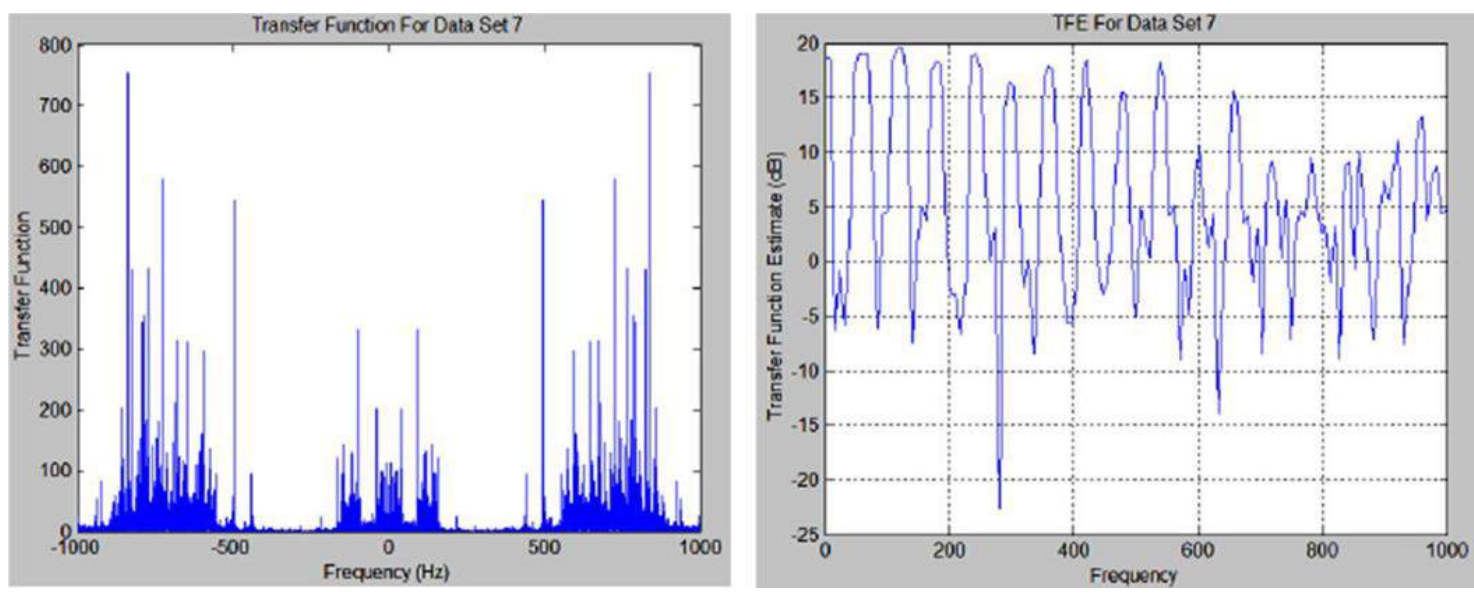

Point 8
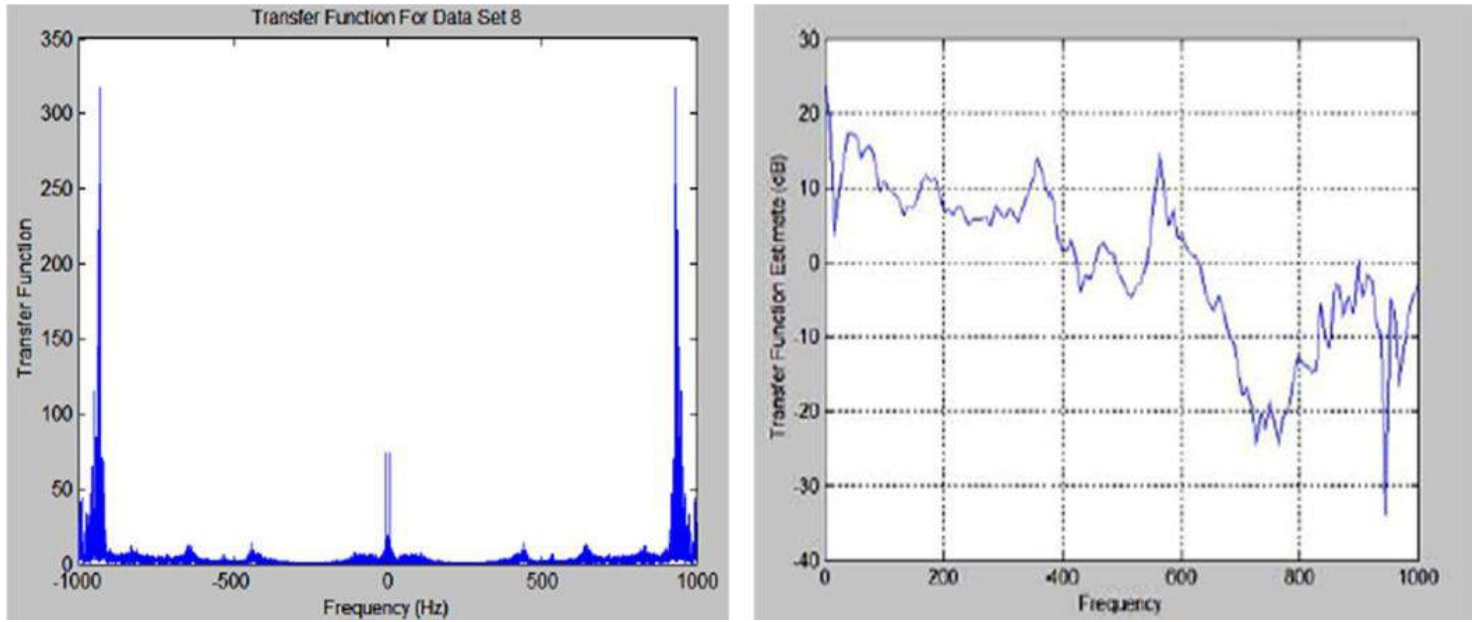

Point 9
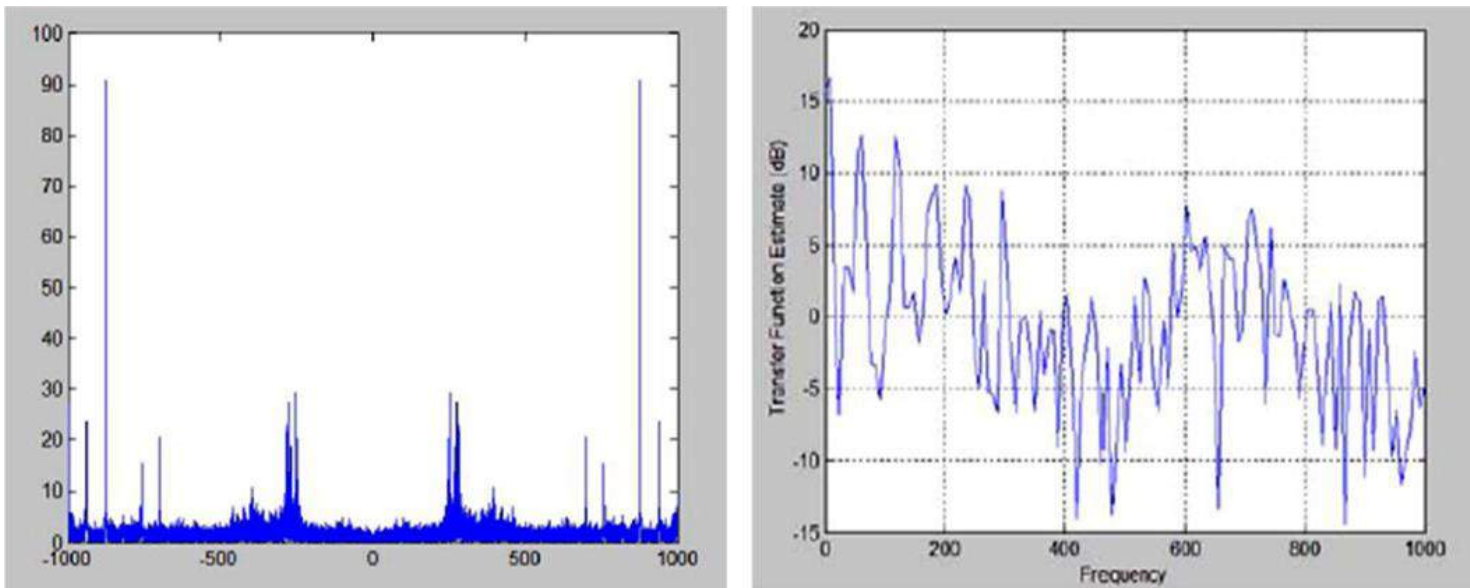
Point 10
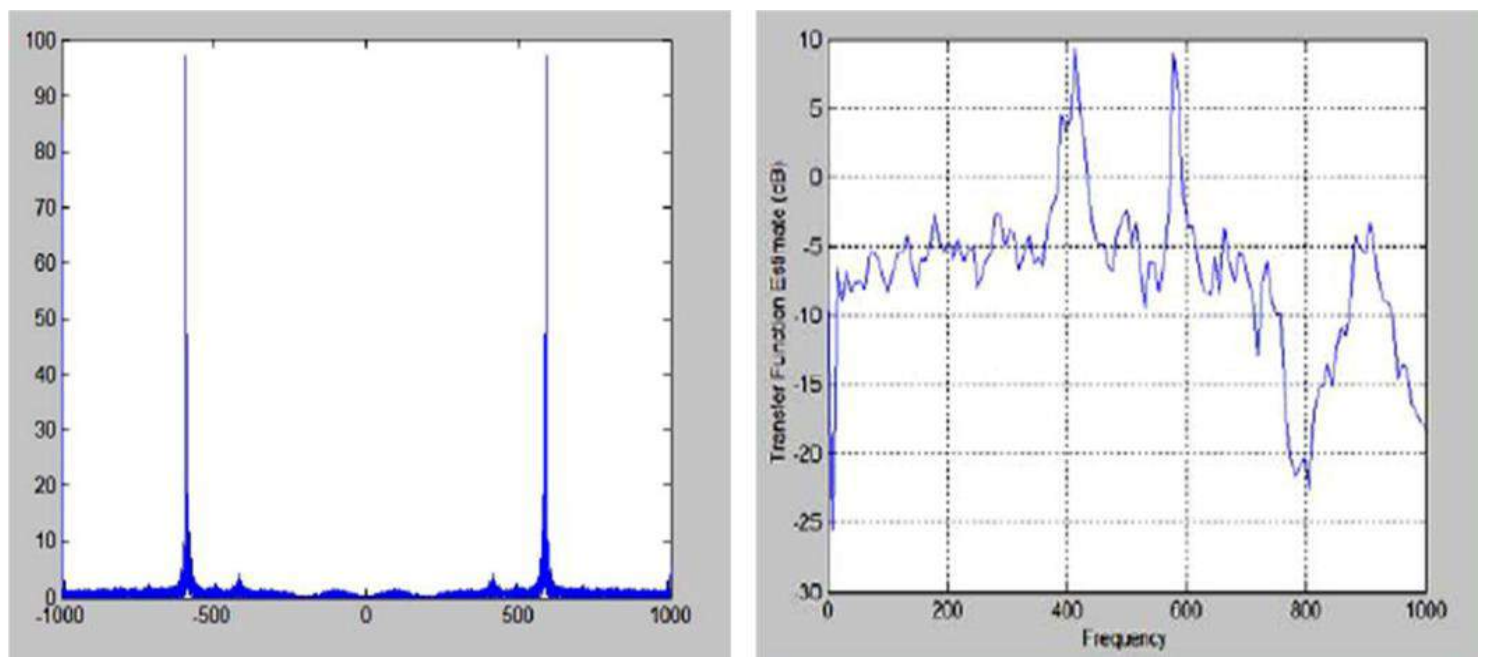

\section{Point 11}
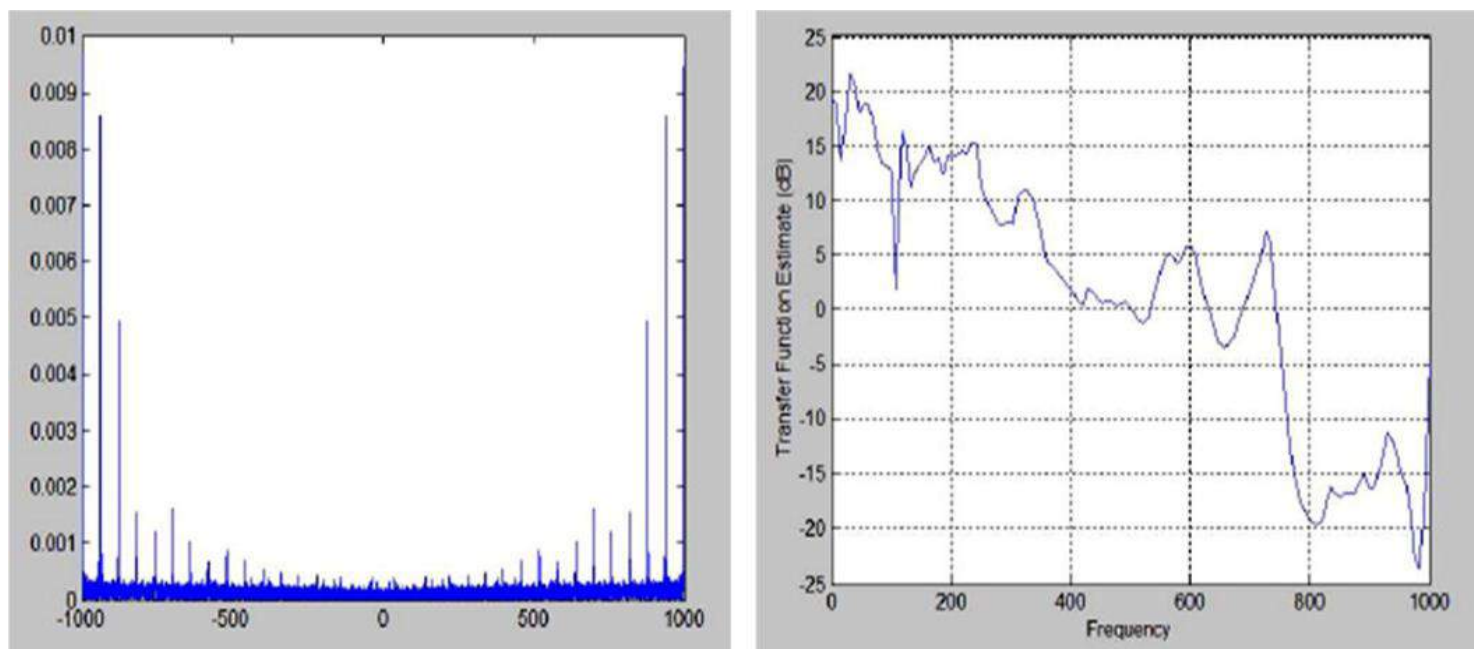

\section{Point 12}
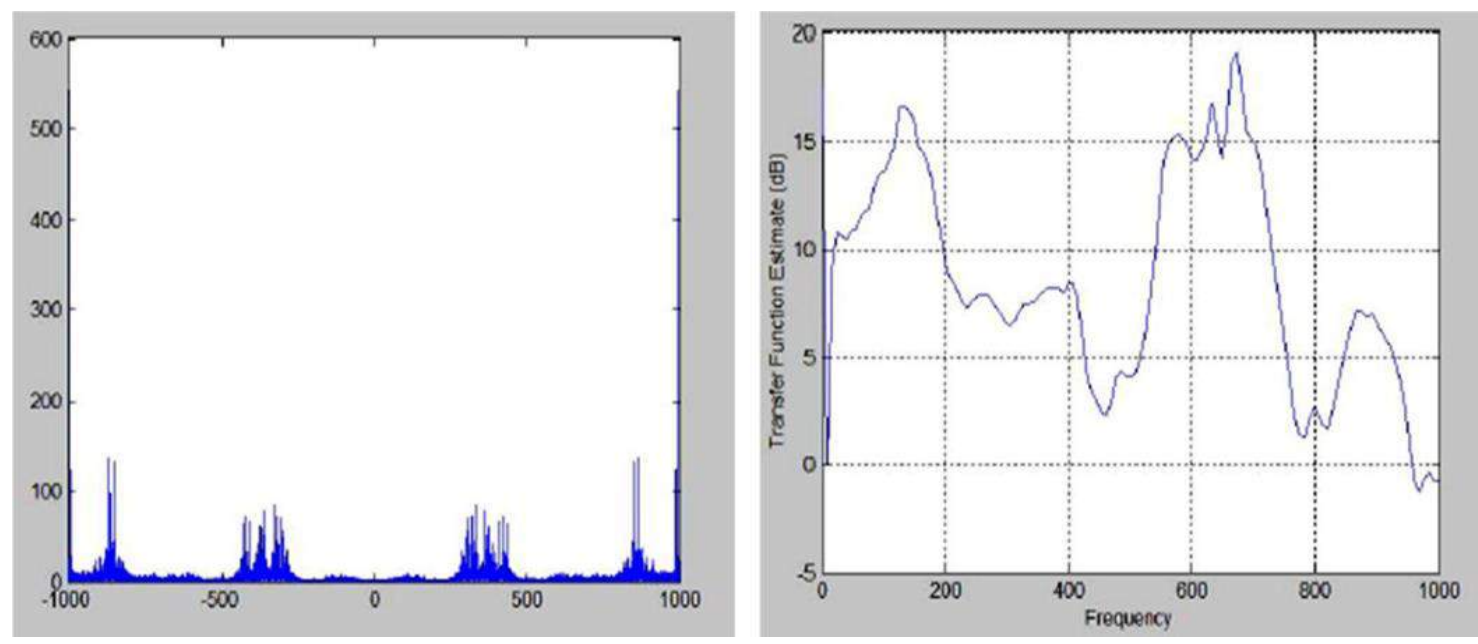